\title{
Analysis and design of complex impedance transforming marchand baluns
}

\section{Michaelsen, Rasmus Schandorph; Johansen, Tom Keinicke; Tamborg, Kjeld M.}

\section{Published in:}

Proceedings of 2014 20th International Conference on Microwaves, Radar, and Wireless Communications

Link to article, DOI:

10.1109/MIKON.2014.6899854

Publication date:

2014

Link back to DTU Orbit

Citation (APA):

Michaelsen, R. S., Johansen, T. K., \& Tamborg, K. M. (2014). Analysis and design of complex impedance transforming marchand baluns. In Proceedings of 2014 20th International Conference on Microwaves, Radar, and Wireless Communications IEEE. https://doi.org/10.1109/MIKON.2014.6899854

\section{General rights}

Copyright and moral rights for the publications made accessible in the public portal are retained by the authors and/or other copyright owners and it is a condition of accessing publications that users recognise and abide by the legal requirements associated with these rights.

- Users may download and print one copy of any publication from the public portal for the purpose of private study or research.

- You may not further distribute the material or use it for any profit-making activity or commercial gain

- You may freely distribute the URL identifying the publication in the public portal 


\title{
Analysis and Design of Complex Impedance Transforming Marchand Baluns
}

\author{
Rasmus S. Michaelsen ${ }^{1,2}$, Tom K. Johansen ${ }^{1}$, Kjeld M. Tamborg ${ }^{2}$, \\ ${ }^{1}$ Technical University of Denmark, Department of Electrical Engineering \\ 2800 Kongens Lyngby, Denmark \\ Email: rsmi@elektro.dtu.dk \\ ${ }^{2}$ Weibel Scientific A/S \\ 3450 Allerød, Denmark
}

\begin{abstract}
A new type of Marchand balun is presented in this paper, which has the property of complex impedance transformation. To allow the Marchand balun to transform between arbitrary complex impedances, three reactances should be added to the circuit. A detailed analysis of the circuit gives the governing equations. To verify the theory, a design and electromagnetic simulation of a lumped element Marchand balun is made in a SiGe BiCMOS technology. The lumped element impementation is favorable because capacitors are placed where the additional reactances should be added. Thus it is possible to absorb a positive reactance by reducing a capacitor. At the design frequency of $\mathbf{1 0 . 5} \mathbf{~ G H z}$ it matches $50 \Omega$ to $50-j 66 \Omega$. It has an insertion loss of $5.1 \mathrm{~dB}$, an input reflection of $-20.8 \mathrm{~dB}$, as well as phase and magnitude imbalance better than $0.2^{\circ}$ and $0.12 \mathrm{~dB}$, respectively.
\end{abstract}

Index Terms-Balun, Marchand balun, Complex impedance transformation, MMIC.

\section{INTRODUCTION}

Baluns are used to transform an unbalanced input signal to a balanced output signal. This is an essential functionality in many microwave circuits, e.g. differential amplifiers and balanced mixers. Baluns can be characterized by a group of parameters. Magnitude balance and phase balance describes how well the balun performs the task of transforming an unbalanced signal to a balanced signal. As for all microwave circuits, input reflection must also be considered. For active baluns gain, noise and linearity is also important parameters. The passive baluns do not suffer from noise or linearity issues, but may suffer from excessive loss. The passive balun has a larger dynamic range, as it does not contribute with neither noise nor decreased linearity.

One type of passive balun structure is the so-called Marchand balun [1]. The Marchand balun consists of two sets of coupled lines connected together. The Marchand type balun has found widespread application, due to its wide bandwidth. Several modifications and enhancements has been reported, among these are techniques for bandwidth enhancement [2], miniturization [3], tuning of phase balance [4] or center frequency [5] and impedance scaling [6]. The impedance scaling is only suggested between real valued generator and load impedances.

The purpose of this paper is to give a suggestion for a Marchand type balun that can do impedance transformation between arbitrary complex impedances. By having the complex impedance matching as part of the balun circuit the total circuit size is minimized, as there is no need for additional matching inductors to the active devices. Also the low-Q of inductors typically found in silicon based technologies make it desirable to avoid them due to added loss.

In [7] the idea of using a coupled line, reactively loaded on the thru and coupled ports, for complex impedance matching was suggested. We will expand this idea to the Marchand balun, constructing it of two of such types of coupled lines. To the authors knowledge, this is the first demonstration of a Marchand balun with complex impedance transformation properties.

This paper will first give an analysis of the proposed impedance transforming Marchand balun. This will be followed by a design suggestion in a SiGe technology. Then we use electromagnetic (EM) simulations on the implementation to verify the analysis and design.

\section{ANALYSIS}

In this section we will provide an analysis of the impedance matching Marchand balun. A schematic of the proposed circuit for the impedance transforming Marchand balun is shown in figure 1 , where port $1\left(P_{1}\right)$ is driven by a generator with impedance $Z_{G}=R_{G}+j X_{G}$ and port $2\left(P_{2}\right)$ and $3\left(P_{3}\right)$ is terminated in $Z_{L}=R_{L}+j X_{L}$.

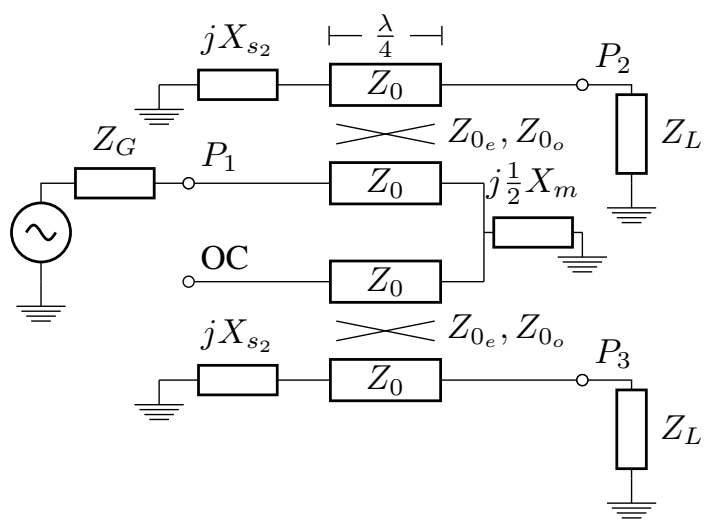

Fig. 1. The modified Marchand balun with complex impedance matching properties. 
The ideal balun behavior for a three port network can be described by S-parameters

$$
\begin{aligned}
& S_{21}=-S_{31} \\
& S_{11}=0 .
\end{aligned}
$$

Ideally, there should be no reflected power from the load and the other S-parameters should not influence performance. Of course this is not the case for real world applications, but the most important ability of a balun is still as expressed above.

To analyze the Marchand balun the approach described in [6] is used. This approach uses the even-/odd-mode analysis [8] to investigate a symmetric network. The balun can be seen as a symmetric four-port with the fourth port terminated in a open circuit. In the analysis we treat the fourth port similar to port one, thus creating a plane of symmetry.

The requirement of balun behavior, i.e. (1) and (2), can be expressed from the even and odd mode circuits, as [6]

$$
\begin{aligned}
T_{\text {even }} & =0 \\
Z_{\text {even }}+Z_{\text {odd }} & =2 Z_{\mathrm{G}}^{*}
\end{aligned}
$$

where $T_{\text {even }}$ is the even mode transmission coefficient, $Z_{\text {even }}$ and $Z_{\text {odd }}$ is the impedance seen into the even and odd mode circuits, respectively, and $Z_{\mathrm{G}}^{*}$ denotes the complex conjugate of $Z_{\mathrm{G}}$.

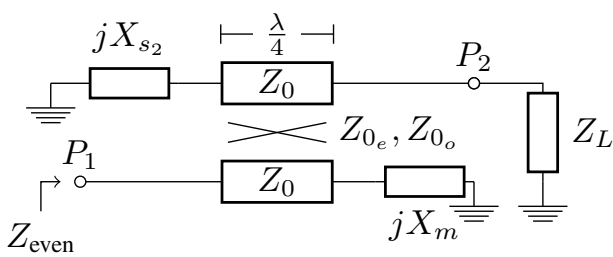

Fig. 2. The even mode circuit.

The even mode circuit of the modified Marchand balun is shown on figure 2. In [7] the two-port Z-parameters for a couple line loaded at the coupled and thru port with $Z_{s_{2}}$ and $Z_{m}$ respectively is given as

$$
\overline{\bar{Z}}=\left[\begin{array}{cc}
\frac{Z_{s_{2}} Z_{+}^{2}}{4 Z_{m} Z_{s_{2}}+Z_{-}^{2}} & \frac{-j Z_{-}}{2}+\frac{\frac{1}{2} j Z_{+}^{2} Z_{-}}{4 Z_{m} Z_{s_{2}}+Z_{-}^{2}} \\
\frac{-j Z_{-}}{2}+\frac{\frac{1}{2} j Z_{+}^{2} Z_{-}}{4 Z_{m} Z_{s_{2}}+Z_{-}^{2}} & \frac{Z_{m} Z_{+}^{2}}{4 Z_{m} Z_{s_{2}}+Z_{-}^{2}}
\end{array}\right]
$$

where $Z_{+}$and $Z_{-}$is $Z_{0 e}+Z_{0 o}$ and $Z_{0 e}-Z_{0 o}$, respectively, $Z_{0 e}$ and $Z_{0 o}$ is the even and odd mode characteristic impedance of the coupled line.

The requirement of (3) is fulfilled if $Z_{21}=0$, which from (5) can be reduced to

$$
4 X_{m} X_{s_{2}}-Z_{-}^{2}+Z_{+}^{2}=0
$$

where it has been used that $Z_{s_{2}}=j X_{s_{2}}$ and $Z_{m}=j X_{m}$. Because of the requirement $Z_{21}=0$ then the even mode impedance is not dependent on the load condition and we have

$$
Z_{\text {even }}=\frac{Z_{s_{2}} Z_{+}^{2}}{4 Z_{m} Z_{s_{2}}+Z_{-}^{2}}
$$

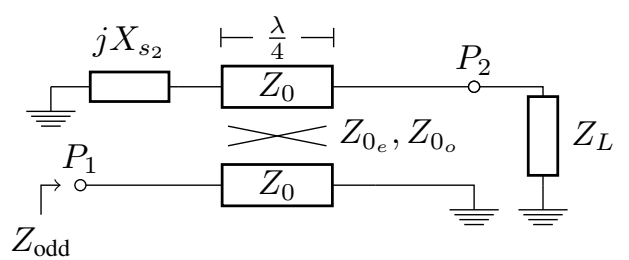

Fig. 3. The odd mode circuit.

The odd mode circuit of the modified Marchand balun is shown on figure 3 , it consists of a coupled line with a reactive load on the coupled port and a short circuit on the thru port. The two port Z-parameters for the odd mode circuit is then given as (5) with $Z_{m}=0$,

$$
\left.\overline{\bar{Z}}\right|_{Z_{m}=0}=\left[\begin{array}{cc}
\frac{Z_{s_{2}} Z_{+}^{2}}{Z_{-}^{2}} & j \frac{Z_{+}^{2}-Z_{-}^{2}}{2 Z_{-}} \\
j \frac{Z_{+}^{2}-Z_{-}^{2}}{2 Z_{-}} & 0
\end{array}\right] .
$$

The odd mode impedance can be found as the input impedance of the loaded two port

$$
Z_{\text {odd }}=\frac{Z_{s_{2}} Z_{+}^{2}}{Z_{-}^{2}}-\frac{\left(Z_{+}^{2}-Z_{-}^{2}\right)^{2}}{4 Z_{-}^{2} Z_{L}} .
$$

By inserting (7) and (9) into (4) and splitting the equation in a real and imaginary part gives

$$
\begin{aligned}
R_{G}= & \frac{1}{8} \frac{\left(Z_{+}^{2}-Z_{-}^{2}\right)^{2} R_{L}}{Z_{-}^{2}\left(R_{L}^{2}+X_{L}^{2}\right)} \\
X_{G}= & \frac{1}{2} \frac{X_{s_{2}} Z_{+}^{2}}{Z_{-}^{2}}-\frac{1}{8} \frac{\left(Z_{+}^{2}-Z_{-}^{2}\right)^{2} X_{L}}{Z_{-}^{2}\left(R_{L}^{2}+X_{L}^{2}\right)} \\
& +\frac{1}{8} \frac{X_{s_{2}} Z_{+}^{2}}{\frac{1}{4} Z_{-}^{2}-X_{m} X_{s_{2}}} .
\end{aligned}
$$

The condition $X_{G}=0$ is chosen to simplify the following equations, but a more general approach is possible also for $X_{G} \neq 0$. The three equations (6), (10) and (11) has four design parameters, $X_{s_{2}}, X_{m}, Z_{0_{o}}$ and $Z_{0_{e}}$ as free variables. From (6) one gets

$$
X_{m}=-\frac{1}{4} \frac{Z_{+}^{2}-Z_{-}^{2}}{X_{s_{2}}}
$$

Then inserting (12) in (11) to get

$$
X_{s_{2}}=\frac{1}{4} \frac{X_{L}\left(Z_{+}^{2}-Z_{-}^{2}\right)^{2}}{\left(Z_{-}^{2}+Z_{+}^{2}\right)\left(R_{L}^{2}+X_{L}^{2}\right)}
$$

Finally from (10) we get

$$
\begin{aligned}
\frac{1}{Z_{0_{o}}}-\frac{1}{Z_{0_{e}}} & =\frac{1}{R_{G}} \sqrt{\frac{2}{\alpha}} \\
\text { where } \alpha & =\frac{R_{L}^{2}+X_{L}^{2}}{R_{G} R_{L}}
\end{aligned}
$$

Observe that for the case of transformation to a real valued load, i.e. $X_{L}=0$, (13) gives $X_{s_{2}}=0$, a short circuit, (12) gives $X_{m} \rightarrow \infty$, an open circuit, and the impedance scaling factor becomes $\alpha=\frac{R_{L}}{R_{G}}$, which is the case for the regular Marchand balun [9]. 


\section{DeSIGN PROCEDURE AND SIMULATION RESUlts}

In this section we will describe the design procedure for the balun. This is followed by a design example and simulations of the design.

\section{A. Design procedure}

The lumped element Marchand balun is chosen to realise the circuit [10]. This has the advantages of small size together with posibility to place capacitors where the added reactances $X_{s_{2}}$ and $X_{m}$ is needed. In figure 4 the schematic is shown. The design procedure follows what is described in [9], with modification to incorporate $X_{s_{2}}$ and $X_{m}$. The design equations is given as

$$
\begin{aligned}
L_{s} & =\frac{Z_{0_{e}}+Z_{0_{o}}}{2 \omega} \\
k & =\frac{Z_{0_{e}}-Z_{0_{o}}}{Z_{0_{e}}+Z_{0_{o}}} \\
C_{c} & =\frac{1}{2 \omega}\left(\frac{1}{Z_{0_{o}}}-\frac{1}{Z_{0_{e}}}\right) \\
C_{s} & =\frac{1}{\omega Z_{0_{e}}} \\
C_{s_{2}} & =C_{s}-\frac{1}{X_{s_{2}} \omega} \\
C_{m} & =2 C_{s}-\frac{2}{\omega X_{m}} .
\end{aligned}
$$

\section{B. Design example}

To test the theory a X-band Marchand balun with transformation of generator impedance of $Z_{g}=50 \Omega$ to a load impedance of $Z_{L}=50-j 60 \Omega$ at $10.5 \mathrm{GHz}$ is designed. The load value is chosen as it corresponds to a typical mixer diode load, being capacitive.

The circuit is designed using a designkit from Innovations for High Performance Microelectronics (IHP) for their $0.25 \mu \mathrm{m} \mathrm{SiGe:C} \mathrm{BiCMOS}$ process. The process has metalinsulator-metal (MIM) capacitors and five metal layers.

The size of the inductor has been the deciding factor in choosing $Z_{0_{e}}=32.5 \Omega$ giving inductor sizes of $L_{s}=0.4 n \mathrm{H}$. In table I the design parameters for the balun are given, both the theoretical values as calculated and the compensated values as implemented. Especially the implementation of the coupled inductors gives problems due to the difficulties of realization of exact $k$ and $C_{c}$, but this can be compensated by changing $C_{m}, C_{s}$, and $C_{s_{2}}$.

Figure 5 shows layout of the proposed implementation. The two sets of coupled inductors has a total size of $423 \mu \mathrm{m} \times$ $194 \mu \mathrm{m}$ and the suggested breakout has a dimension of $610 \mu \mathrm{m} \times 930 \mu \mathrm{m}$. The dimensions of the breakout could also be used in a real circuit to avoid undesired coupling.

\section{Simulation Results}

Electromagnetic simulations using Momentum in Agilent ADS has been used to verify the design implementation. Due to designkit limitations the capacitors is not part of the Momentum simulation, but models is included in an Agilent

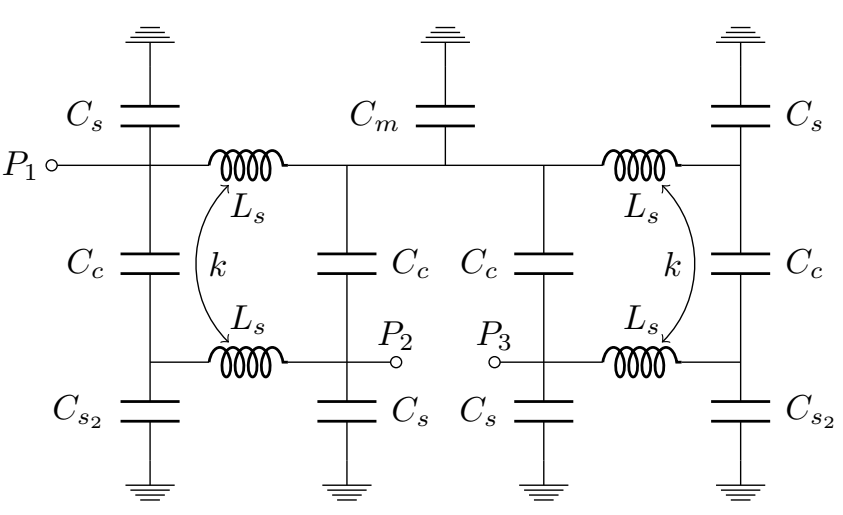

Fig. 4. The lumped element implementation of the Marchand balun with complex matching properties.

TABLE I

DESIGN PARAMETERS FOR THE BALUN

\begin{tabular}{lccrr}
\hline Description & \multicolumn{2}{c}{ Symbol } & Calc. & Comp. \\
\hline Even mode characteristic impedance & $Z_{0_{e}}$ & {$[\Omega]$} & 32.5 & \\
Odd mode characteristic impedance & $Z_{0_{o}}$ & {$[\Omega]$} & 20.9 & \\
Reactance, side & $X_{s_{2}}$ & {$[\Omega]$} & -5.96 & \\
Reactance, middle & $X_{m}$ & {$[\Omega]$} & 114 & \\
Inductance & $L_{s}$ & {$[n H]$} & 0.4 & 0.4 \\
Inductive coupling & $k$ & & 0.21 & 0.15 \\
Capacitive coupling & $C_{c}$ & {$[f F]$} & 129 & 157 \\
Side capacitor & $C_{s}$ & {$[f F]$} & 466 & 305 \\
Increased side capacitor & $C_{s_{2}}$ & {$[p F]$} & 3.01 & 2.6 \\
Middle capacitor & $C_{m}$ & {$[f F]$} & 667 & 727 \\
\hline
\end{tabular}

ADS S-parameter simulation. The resulting S-parameters are plotted in Figure 6. At the design frequency, an insertion loss of $5.1 \mathrm{~dB}$ is simulated, together with a reflection of $-20.8 \mathrm{~dB}$. The phase imbalance is $0.2^{\circ}$ and the magnitude imbalance is $0.12 \mathrm{~dB}$. Figures 7 and 8 shows plots of the magnitude and phase difference from 8 to $14 \mathrm{GHz}$. The bandwidth is limited by the matching from $10.1 \mathrm{GHz}$ to $10.8 \mathrm{GHz}$ if a reflection below $-15 \mathrm{~dB}$ is desired. In this band the insertion loss is better than $5.5 \mathrm{~dB}$, the phase imbalance better than $0.3^{\circ}$, and the magnitude imbalance better than $0.16 \mathrm{~dB}$.

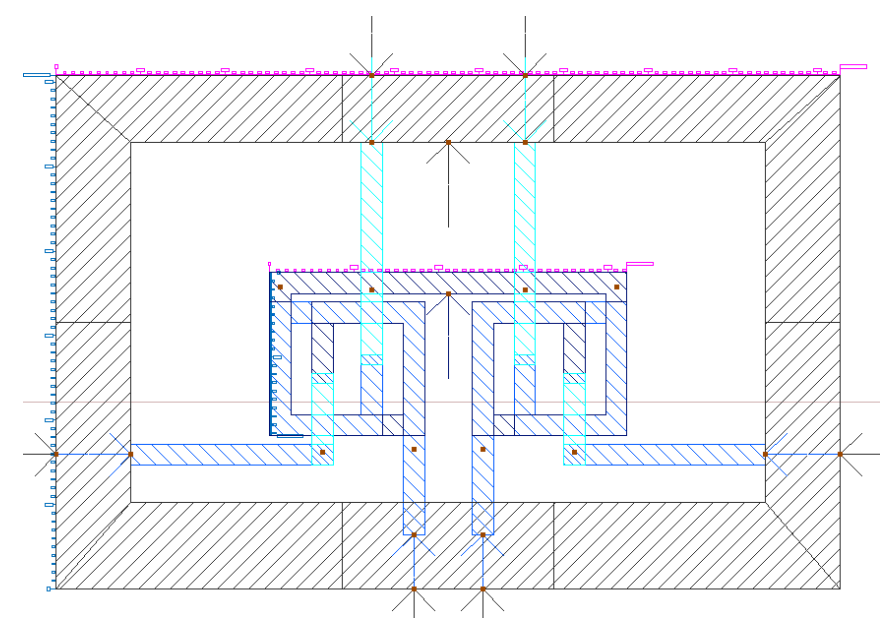

Fig. 5. Layout of proposed circuit, dimensions are $610 \mu m \times 930 \mu m$. 


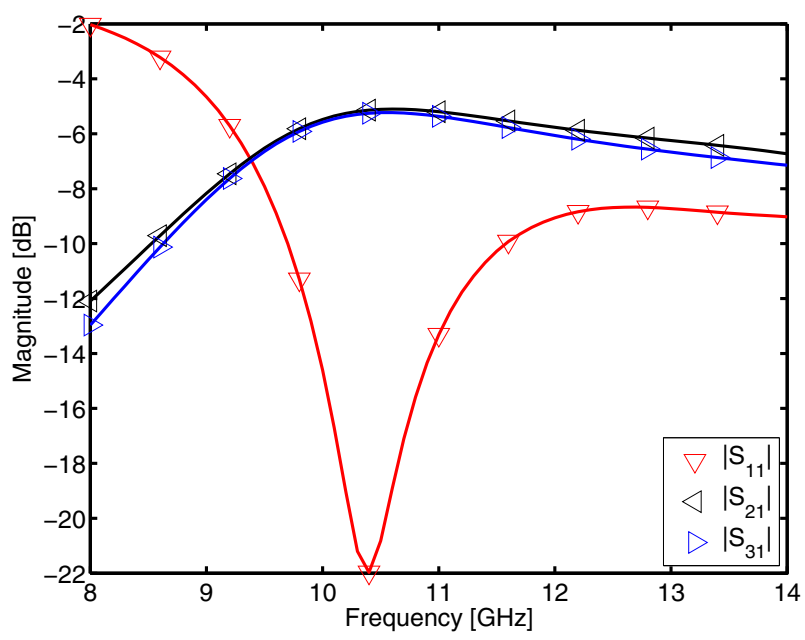

Fig. 6. Magnitude of S-parameters for the proposed balun circuit.

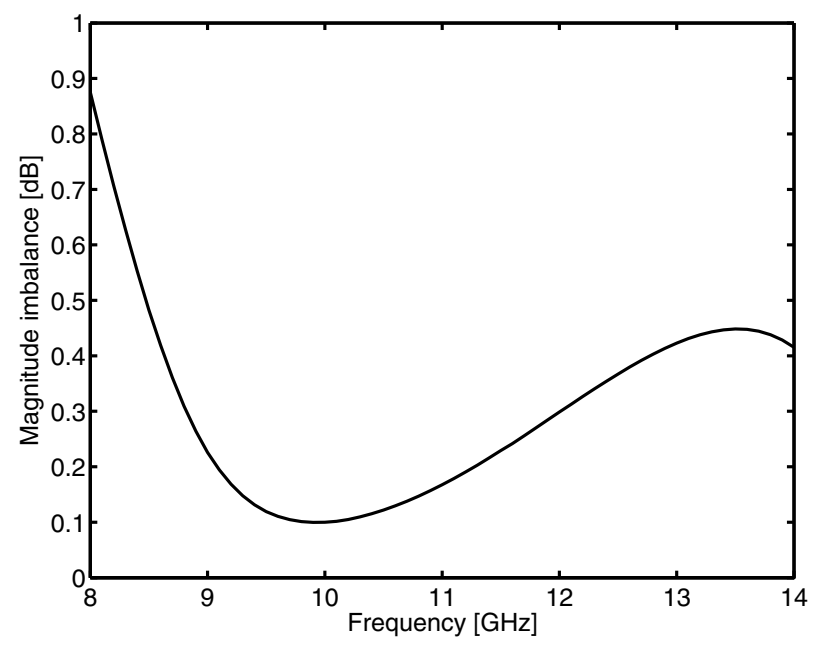

Fig. 7. Magnitude imbalance at the output for the proposed balun circuit.

\section{CONCLUSION}

In this paper the novel idea of a complex impedance transforming Marchand balun was discussed. A detailed analysis gives the governing equations for realization of such a circuit. It was shown, that by addition of three reactances together with careful selection of even and odd mode characteristic impedance an arbitrary complex impedance match can be obtained.

A lumped element implementation of the complex impedance transforming Marchand balun was designed and EMsimulated. The lumped element impementation has the property of having capacitors placed where the additional reactances should be added anyway. Thus it is possible to absorb a positive reactance by reducing a capacitor and a negative by increasing a capacitor. With this design approach no additional inductances are needed for matching, thus reducing loss and circuit size.

The simulation showed that matching to a $50-j 66 \Omega$ load

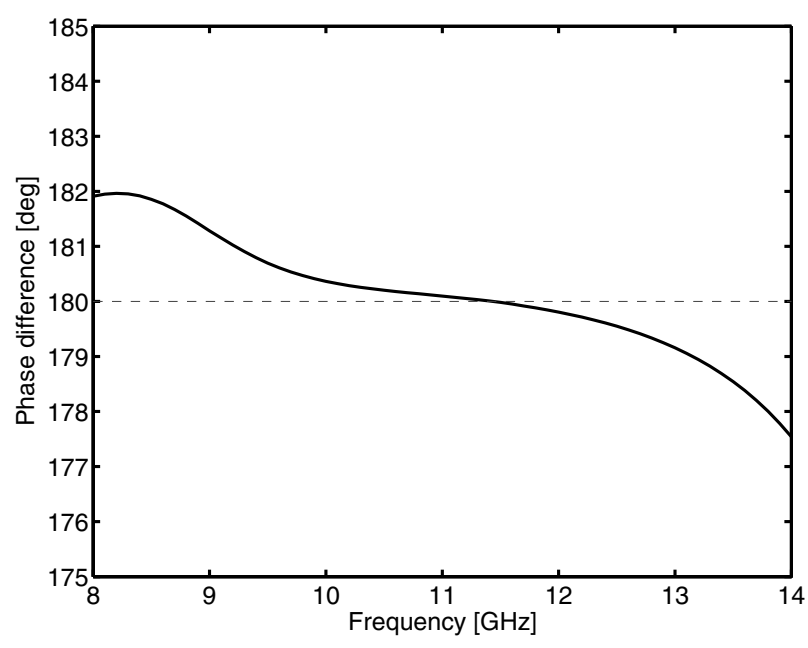

Fig. 8. Phase difference of the two output ports of the proposed balun circuit.

impedance was possible. An input reflection of $-20.8 \mathrm{~dB}$ at the design frequency of $10.5 \mathrm{GHz}$, and a insertion loss of 5.1 $\mathrm{dB}$ was simulated. The phase and magnitude imbalance was better than $0.2^{\circ}$ and $0.12 \mathrm{~dB}$, respectively. The bandwidth is limited to the range from $10.1 \mathrm{GHz}$ to $10.8 \mathrm{GHz}$ for a input reflection better than $-15 \mathrm{~dB}$. In this band the insertion loss is better than $5.5 \mathrm{~dB}$, the phase imbalance better than $0.2^{\circ}$, and the magnitude imbalance better than $0.16 \mathrm{~dB}$.

\section{REFERENCES}

[1] N. Marchand, "Transmission-line conversion transformers," Electronics, vol. 17, pp. 142-145, 1944.

[2] J.-C. Lu, C.-C. Lin, and C.-Y. Chang, "Exact Synthesis and Implementation of New High-Order Wideband Marchand Baluns," IEEE Transactions on Microwave Theory and Techniques, vol. 59, no. 1, pp. 80-86, 2011.

[3] L. Xu, H. Sjoland, M. Tormanen, T. Tired, T. Pan, and X. Bai, "A Miniaturized Marchand Balun in CMOS With Improved Balance for Millimeter-Wave Applications," IEEE Microwave and Wireless Components Letters, vol. 24, no. 1, 2014.

[4] R. Michaelsen, T. Johansen, K. Tamborg, and V. Zhurbenko, "A Modified Marchand Balun Configuration With Tunable Phase Balance," I E E E Microwave and Wireless Components Letters, vol. 23, no. 2, pp. 66-68, 2013.

[5] X. Miao, W. Zhang, Y. Geng, X. Chen, R. Ma, and J. Gao, "Design of Compact Frequency-Tuned Microstrip Balun," IEEE Antennas and Wireless Propagation Letters, vol. 9, pp. 686-688, 2010.

[6] K. S. Ang, Y. C. Leong, and C. H. Lee, "Analysis and design of miniaturized lumped-distributed impedance-transforming baluns," Microwave Theory and Techniques, IEEE Transactions on, vol. 51, no. 3, pp. 1009 - 1017, mar 2003.

[7] T. Jensen, V. Zhurbenko, V. Krozer, and P. Meincke, "Coupled Transmission Lines as Impedance Transformer," IEEE Transactions on Microwave Theory and Techniques, vol. 55, no. 12, pp. 2957-2965, 2007.

[8] J. Reed and G. Wheeler, "A Method of Analysis of Symmetrical FourPort Networks," IRE Transactions on Microwave Theory and Techniques, vol. 4, no. 4, pp. 246-252, 1956.

[9] R. Michaelsen, T. Johansen, K. Tamborg, and V. Zhurbenko, "Design of a Broadband Passive X-Band Double Balanced Mixer in SiGe HBT technology," To appear in International Journal of Microwave and Wireless Technologies, 2014.

[10] T. Johansen and V. Krozer, "Analysis and Design of Lumped Element Marchand Baluns," in 2008 MIKON CONFERENCE PROCEEDINGS. IEEE, 2008, pp. 672-675. 